\title{
Two Xylella fastidiosa Genotypes Associated with Almond Leaf Scorch Disease on the Same Location in California
}

\author{
J. Chen, R. Groves, E. L. Civerolo, M. Viveros, M. Freeman, and Y. Zheng
}

First, second, and third authors: Agricultural Research Service, U.S. Department of Agriculture, Parlier, CA 93648; fourth author: University of California Cooperative Extension, Bakersfield 93307; fifth author: University of California Cooperative Extension, Fresno 93702, and sixth author: Your-Way Consulting, Fresno, CA 93729.

Accepted for publication 16 February 2005.

\begin{abstract}
Chen, J., Groves, R., Civerolo, E. L., Viveros, M., Freeman, M., and Zheng, Y. 2005. Two Xylella fastidiosa genotypes associated with almond leaf scorch disease on the same location in California. Phytopathology 95:708-714.

Almond leaf scorch disease (ALSD) has recently reemerged in the San Joaquin Valley of California threatening almond production. ALSD is caused by Xylella fastidiosa, a nutritionally fastidious bacterium. Single nucleotide polymorphisms (SNPs) in the 16S rRNA gene (16S rDNA) of $X$. fastidiosa strains were identified to characterize the bacterial population in infected trees. Genotype-specific SNPs were used to design primers for multiplex polymerase chain reaction assays of early passage

cultures. Two genotypically distinct types of $X$. fastidiosa strains, G-type and A-type, coexist simultaneously in the same infected almond orchard. This was substantiated by restriction fragment length polymorphism analysis of a different genetic locus, RST31-RST33, which has previously been used to identify and differentiate $X$. fastidiosa strains. Furthermore, unique bacterial colony morphology was consistently associated with the A-type $X$. fastidiosa strains. To our knowledge, this is the first report of a mixed genotype infection of $X$. fastidiosa disease on the same location under natural environmental conditions. The concept of mixed genotype infection could affect the current epidemiological study based on the assumption that one genotype causes ALSD on one location and, therefore, the disease management strategy.
\end{abstract}

Almond leaf scorch disease (ALSD) has recently reemerged as a serious disease threatening almond production in the San Joaquin Valley of California (2). The bacterial etiology of ALSD was initially based on electron microscopic examination of symptomatic leaves from infected almond trees (18) and subsequently confirmed by fulfilling Koch's postulate (10). The pathogen is taxonomically classified as Xylella fastidiosa, a nutritionally fastidious, xylem-limited bacterium (29). Leaf scorching during the summer and fall is the most noticeable symptom of ALSD, although this symptom can be easily confused with those of other disorders such as salt toxicity. Disease confirmation relies on pathogen identification, often accomplished by enzyme-linked immunosorbent assay, specific polymerase chain reaction (PCR), and bacterial growth characteristic in axenic cultivation. These techniques identify the pathogen at the species level.

Genetic and pathogenic variation of $X$. fastidiosa is an important factor affecting disease epidemiology and control. Previous research on $X$. fastidiosa has focused on the etiology of a single pathotype present in a susceptible host. The ALSD pathogen was reported to cause Pierce's disease (PD) following insect vector transmission to grapevines (18). Based on reciprocal pathogenicity tests, Davis et al. (10) concluded that both ALSD and PD were caused by the same pathogenic strains. We consider each bacterial isolate as a strain. Recently, two studies using strains sampled from different locations in California identified that ALSD could be caused by two distinct genotypes, one could cause PD and the other could not $(2,12)$. In these studies, all strains in the non-PD group were isolated from northern counties

Corresponding author: J. Chen; E-mail address: jichen@ fresno.ars.usda.gov

DOI: 10.1094/PHYTO-95-0708

This article is in the public domain and not copyrightable. It may be freely reprinted with customary crediting of the source. The American Phytopathological Society, 2005 of the Central Valley of California. The strains identified in the PD group were from southern areas of the Central Valley.

The possibility of natural mixed infection by multiple genotypes in a single location as well as a single plant has not yet been demonstrated in the $X$. fastidiosa pathosystem, although $X$. fastidiosa strains have a very broad host range (11) with no reported vector specificity. It is assumed that plant hosts can be exposed to multiple $X$. fastidiosa strains. Recognition of mixed infection is important for disease study and control. In phloem-limited and leafhopper-vectored phytoplasma pathosystems, mixed genotype infections have been known to influence the disease symptomatology and epidemiology $(1,15,25)$.

The lack of documentation of mixed genotype infections of $X$. fastidiosa is probably due to the lack of efficient research tools. Currently, $X$. fastidiosa strains are differentiated by pure culturedependent, DNA polymorphism-based methods such as randomly amplified polymorphic DNA (RAPD), restriction fragment length polymorphism (RFLP) analyses, etc. These techniques are not applicable to mixed genotype samples because of the lack of specificity to a genotype. There is a need for a technique that can simultaneously identify $X$. fastidiosa species and differentiate the genotypes. We propose that a conserved genomic region could be used for species recognition and that a single nucleotide polymorphism (SNP) within the conserved region could be used to differentiate genotypes below the species level.

In this study, we developed an SNP-based PCR to identify and differentiate $X$. fastidiosa strains collected from ALSD-affected almond. The $16 \mathrm{~S}$ rRNA gene was chosen because (i) $16 \mathrm{~S}$ rRNA gene sequences are highly conserved at the species level, making them good candidates for species identification $(5,22)$; (ii) SNPs exist in the $16 \mathrm{~S}$ rDNA sequences and are key elements in forming subspecies level clusters $(7,16)$; and (iii) $16 \mathrm{~S}$ rRNA genes are currently the most sequenced locus in bacteria. SNPs derived from a large number of sequences provide a higher level of reliability. Using the SNP-based PCR, we examined the mixed infection 
of X. fastidiosa genotypes from ALSD samples on the same location.

\section{MATERIALS AND METHODS}

Isolation of $X$. fastidiosa from ALSD samples. ALSDaffected almond trees were sampled in orchards in Fresno, Kern, Stanislaus, and Tulare counties in the San Joaquin Valley, and in Butte and Solano counties in the Sacramento Valley of California. Samples were collected between September and November 2003, when leaf scorching symptoms were the most visible. Small branches with symptomatic leaves were excised, placed in labeled plastic bags, and transported to the San Joaquin Valley Agricultural Sciences Center, Parlier, CA. Upon arrival, samples were stored at $4{ }^{\circ} \mathrm{C}$ and processed for isolation within $24 \mathrm{~h}$.

Petioles were separated from leaf blades and surface-sterilized in $1 \%$ sodium hypochlorite for 2 min followed by three rinses in sterile, de-ionized water. Two transverse incisions were made in each petiole equally spaced along the length of the petiole. Xylem sap was expressed aseptically with a pair of flame-sterilized, needle-nose pliers onto the sterile surface of a petri dish. A drop of periwinkle wilt (PW) broth (9) was immediately added and mixed with the sap. One loopful of the sap mixture was then streaked on PW medium solidified by Gel-Rite (PWG, 13) and incubated at $28^{\circ} \mathrm{C}$. The appearance of opalescent colonies was monitored with a binocular microscope for up to 40 days. Candidate strains were transferred onto fresh PWG, their identity tested by PCR with primer set RST31-RST33 (17), and subjected to genotyping within three passages of subculturing. To obtain a pure strain from the early passage and presumably genotypemixed culture, single colonies were triple-cloned. The reference strains of $X$. fastidiosa, Temecula and Dixon, were provided by A. Purcell (University of California at Berkeley).

Identification of SNPs and PCR primer designs. A total of 38 16S rDNA sequences from different sources $(4,7,16,20,24,27$, 29) were retrieved from the GenBank database. These sequences were aligned using the CLUSTAL-W software (26) through the network service of the European Bioinformatics Institute (EBI) (available online by EBI). SNPs were initially identified by comparison of the sequences from $X$. fastidiosa strains Temecula, Dixon, Ann-1, and 9a5c. The authenticity and reliability of SNPs was further substantiated by comparative analysis of multiple sequences from different sources $(7,16,20,29)$. The nucleotide order in the 16S ribosomal RNA gene, or open reading frame PD0048, in the $X$. fastidiosa strain Temecula genome sequence (27) was used as a reference to standardize the nucleotide position. Strain Temecula was used to represent the PD-causing ALSD strains, and strain Dixon was used to represent non-PD-causing ALSD strains.

Primer 3 software (21) was used to facilitate primer design. The desired $T_{m}$ of all primers was set to $60 \pm 3^{\circ} \mathrm{C}$. The strategy for primer design is illustrated in Figure 1. In principle, a specific primer was designed by placing an SNP at the $3^{\prime}$ end as previously described (3). Two multiplex PCR formats were developed. For the three primer format, primers Teme150fc and Teme454rg matched the nucleotides from strain Temecula at the SNP positions. This primer set generated a calculated 348-bp amplicon for $X$. fastidiosa strain Temecula, but not strain Dixon due to the two 3' mismatches. Considering the possibility of no amplification, where PCR failure could be implied, a third primer, XF16s1031r, conserved to all known $X$. fastidiosa strains, was added (Fig. 1). In the presence of a non-Temecula-type strain, the alternative primer set, Teme150fc-XF16s1031r, has only one mismatch to the DNA template. Under this circumstance, the amplicon could still be made but in the size of 700 bp (Fig. 1). The amplification serves as a positive control for a successful PCR reaction and the 700-bp amplicon size indicates the presence of a non-Temecula strain genotype.

In the four primer format, two primer sets were used. In addition to Teme150fc-Teme454rg as in the three primer format, the other primer set, Dixon454fa-Dixon1261rg, generated an 847-bp amplicon from strain Dixon. In fact, primer Dixon454fa and primer Teme454rg overlapped the same SNP position (Fig. 1). To check for specificity, each primer sequence was compared with the nonredundant, GenBank bacterial sequence database through the BLAST network service at the National Center for Biotechnology Information (provided online by NCBI). To test a primer pair, the two primers sequences were concatenated with 40 arbitrarily selected ambiguous nucleotides in between. The concatenated sequence was used for BLASTn search.

Analysis of RST31-RST33 locus. Primer set RST31-RST33 (17) was used for PCR confirmation of X. fastidiosa at the species level. For further strain differentiation, RST31-RST33 amplicons were digested with $R s a \mathrm{I}$ for $1 \mathrm{~h}$ at $37^{\circ} \mathrm{C}$ (17). RFLPs were identified by $1.5 \%$ agarose gel electrophoresis and ethidium bromide staining. To further analyze the DNA polymorphism at the nucleotide sequence level, sequences flanked by RST31 and RST33 from the completely sequenced genome of the four $X$. fastidiosa strains were identified through a BLASTn search using the sequence from strain Temecula as query and the result was pre-
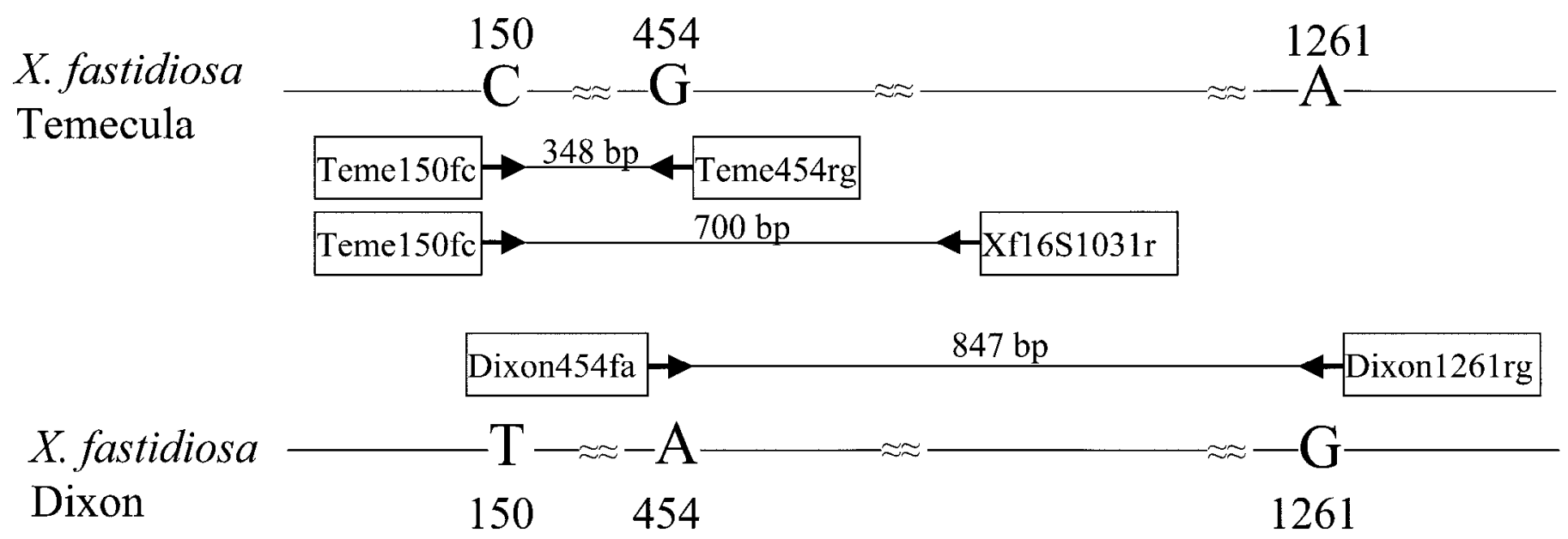

Fig. 1. Primer designs based on single nucleotide polymorphisms in 16S rDNA sequences from Xylella fastidiosa strains Temecula (top) and Dixon (bottom). Three single nucleotide polymorphic positions $(150,454$, and 1261) are indicated; $\approx$ represents multinucleotides. Primers and their amplicons are presented. Teme150fc $=5^{\prime}$ tctaccttat cgtgggggac $3^{\prime}$, Teme454rg $=5^{\prime}$ aacaactagg tattaaccaa ttgcc $3^{\prime}$, Xf16s $1031 \mathrm{r}=5^{\prime}$ aaggcaccaa tccatctctg $3^{\prime}$, Dixon454fa $=5^{\prime}$ cctttgttg gggaagaaaa $3^{\prime}$, and Dixon1261rg $=5^{\prime}$ tagctcacce tcgegagatc $3^{\prime}$. 
sented in a multiple alignment format. Nucleotide variations were identified based on the sequence alignment.

PCR amplification. DNA templates were prepared by suspending a loopful of cell culture in PWG in $100 \mu \mathrm{l}$ of sterile water. PCR $(25 \mu \mathrm{l})$ was carried out using the Takara Taq (Hot Start Version) kit (Takara Bio Inc., Otsu, Japan). The reaction mixture contained $10 \mathrm{mM}$ Tris- $\mathrm{HCl}, \mathrm{pH} 8.3 ; 50 \mathrm{mM} \mathrm{KCl} ; 1.5 \mathrm{mM} \mathrm{MgCl}$; $100 \mu \mathrm{M}$ each dNTPs; $400 \mathrm{mM}$ of each primer; 1 unit of Taq DNA polymerase; and $1 \mu \mathrm{l}$ of cell suspension. Amplification was conducted in a thermocycler (Model PTC-100; MJ Research, Waltham, MA) with an initial denature at $96^{\circ} \mathrm{C}$ for $10 \mathrm{~min}$ followed by 30 cycles consisting of denaturing at $96^{\circ} \mathrm{C}$ for $30 \mathrm{~s}$, annealing at $55^{\circ} \mathrm{C}$ for $30 \mathrm{~s}$, and extension at $72^{\circ} \mathrm{C}$ for $30 \mathrm{~s}$. The amplification products were then stored at $4^{\circ} \mathrm{C}$. The amplified DNAs were resolved through $1.5 \%$ agarose gel electrophoresis and visualized by ethidium bromide staining.

Culture morphology. Bacterial cultures were streaked to single colonies on PWG. Ten to twenty days was usually required for optimum visualization of some colony characteristics. Bacterial colony morphology was examined under a stereo binocular microscope with fiber-optic bifurcated lights. Images were recorded with a DP12 microscopic digital camera (Olympus Optical Ltd., Tokyo, Japan).

\section{RESULTS}

Isolation for $\boldsymbol{X}$. fastidiosa. A total of 303 isolations were attempted. Of these, 178 samples from all six counties were positive for $X$. fastidiosa. The number of bacterial colonies varied considerably ranging from fewer than 5 colonies per plate to more than 250 colonies per plate. Growth of presumptive $X$. fastidiosa colonies required at least 3 days or, typically, 5 to 10 days. In some cases, this required 20 days. The longer incubation period was most often associated with fewer $(<10)$ bacterial colonies, an indication of low bacterial titer in the samples. In the isolationnegative plates, prolonging the incubation time to 40 days did not result in additional bacterial growth. Most of the early isolations were from a small number $(<8)$ of ALSD samples in various orchards. The $X$. fastidiosa strains were later proved to be either A-type or G-type. To prove the presence of mixed genotypes in the same orchard, four orchards in Fresno and Kern counties were subjected to more systematical analysis with a larger number of sampling (Table 1).

One common method of $X$. fastidiosa isolation from petioles is to blot expressed plant sap directly onto medium (14). Because of the soft surface of PWG and the limited amount of xylem sap expressed, a sap-blotted surface was often indented, interfering with later bacterial colony observation. Blotting the xylem sap on the sterile surface of a petri dish and streaking the sap mixture on a PWG plate eliminated problems associated with colony observation.

Identification of SNPs and primer designs. Four SNPs were identified from the alignment of 38 16S rDNA sequences, and the three SNPs related to ALSD strains used in this study were shown in Figure 1. The cytidine in position 150 and guanosine in position 454 separated all of the eight grape and a mulberry strain sequences from the others (data not shown). These nine sequences

TABLE 1. Summary of Xylella fastidiosa isolation and genotyping from almond leaf scorch disease samples from selected orchards in the San Joaquin Valley of California

\begin{tabular}{lccccccc}
\hline & & \multirow{2}{*}{$\begin{array}{c}\text { Sample } \\
\text { County }\end{array}$} & Orchard & size & Cultures & \multirow{2}{*}{$\begin{array}{c}\text { RST31/33 } \\
\text { positive }\end{array}$} & \multicolumn{2}{c}{ positive } & G-type & A-type \\
\hline Fresno & $\mathrm{A}$ & 22 & 4 & 4 & 1 & 3 \\
Fresno & $\mathrm{B}$ & 22 & 7 & 7 & 5 & 2 \\
Kern & $\mathrm{C}$ & 16 & 7 & 7 & 7 & 0 \\
Kern & $\mathrm{D}$ & 83 & 67 & 67 & 18 & 49 \\
\hline
\end{tabular}

originated from four separate laboratories $(7,16,20,27)$. The two SNPs were chosen as markers for the strain Temecula genotype and designated as G-type, referring to the grape representation as well as the guanosine in position 454 . The guanosine at position 1261 was characteristic of a group of $X$. fastidiosa strains from a wide range of hosts. One of them was the Dixon strain causing ALSD. We designated strains in this group as A-type, referring to the almond representation as well as the adenosine in position 454, which was later used for ALSD primer design.

The BLASTn search result from each primer sequence identified $X$. fastidiosa as the most, or one of the most, similar bacteria. No single bacterium, with the exception of $X$. fastidiosa, simultaneously matched to two primers or a primer set, i.e., Teme150fc-Teme454rg, Teme150fc-Xf16s1031r, and Dixon454faDixon1261rg (data not shown). The specificity of the three primer sets was further demonstrated when the primer concatenated sequence was used for BLASTn search where $X$. fastidiosa was the only bacterial species to have hits for both primers (data not shown).

In addition to species specificity of the PCR primers, the SNPs at the $3^{\prime}$ end of these primers allowed for the differentiation of genotypes, or A-type and G-type, of X. fastidiosa. Since Teme131fc-Teme478rg has no base variation in the G-type strains, the primer set detected this genotype with a 348-bp amplicon (Fig. 2A). Under the PCR stringency used, the two $3^{\prime}$ end mismatches were sufficient to block the specific DNA amplification from non-G-type strains, or to yield a substantially weaker amplification (Fig. 2A, strain Dixon). The other primer combination, Teme131fc-Xf16s1031r, was however able to generate a 700-bp DNA amplicon identifying a non-G-type strain (Fig. 2A).

Based on the available information $(2,12)$, the non-G-type detected by the three primer PCR format was presumably an A-type. The four primer multiplex PCR format was used to confirm this assumption. In the four primer multiplex PCR format, primer set Teme131fc-Teme478rg generated a 348-bp DNA amplicon as expected and primer set Dixon435fa-Dixon1128rg produced an 847-bp amplicon (Figs. 1 and 2B). For the strains examined in this study, results from the two multiplex PCR formats always agreed.

Analysis of RST31-RST33 locus. PCR using primer set RST31-RST33 generated an expected 721-bp amplicon, confirming the $X$. fastidiosa identity of the ALSD strains studied (Fig. 2C). RST31-RST33 amplicons from G-type strain could not be digested by RsaI; yet, for A-type strains, two DNA fragments (149 and 572 bp) were evidenced (Fig. 2D). These results were expected and consistent with the SNP analyses. In Figure 2D, incomplete $R s a$ I digestion of A-type strain amplicons was apparent, but this did not interfere with the interpretation of strain differentiation. Overnight $R s a \mathrm{I}$ incubation, rather than $1 \mathrm{~h}$, resulted in complete DNA digestion (data not shown). It should be noted that the genomic locus flanked by RST31-RST33 was physically independent from the two identical rrn loci in the $X$. fastidiosa genome. Based on the information from the whole genome sequence annotation $(24,27)$, the RST31-RST33 DNA sequence has $502 \mathrm{bp}$ in the $3^{\prime}$ end of gene rpoD, coding for an RNA polymerase sigma-70 factor, and $219 \mathrm{bp}$ in the downstream intergenic region. An SNP within an $R s a$ I site covering position 572 (G in strain Temecula and A in strain Dixon) was responsible for the RFLP difference between the G-type (Temecula) and the A-type (Dixon) strains.

Sequence comparisons further demonstrated that two bases downstream of the SNP was a repeat sequence of two 14 bp units in the CVC-9a5c genome (data not shown). Such a repeat does not occur in strains Temecula, Dixon, and Ann-1. Because of the sequence repeat, the RST31-RST33 amplicon from CVC-9a5c should be 735 bp compared with the 721 bp in strains Temecula and Dixon. The size of the RST31-RST33 amplicon from strain Ann-1 was 723 bp. The original publication reported a 733-bp 
amplicon from a Florida PD strain (17). In all case, these nucleotide variations were too small to be differentiated in agarose gel electrophoresis.

Detection of different $X$. fastidiosa genotypes in ALSD samples. Both G-type and A-type strains were identified from samples collected from ALSD-affected orchards within the San Joaquin Valley in 2003 as shown in Table 1. The two orchards (A and B) in Fresno County were located approximately $4 \mathrm{~km}$ apart and each contained both strain types of $X$. fastidiosa. In Kern County, sampling from orchard $\mathrm{C}$ yielded only the G-type. However, results from the larger, systematically sampled orchard D, which was approximately $2.4 \mathrm{~km}$ from orchard C, showed the presence of both A-type and G-type of X. fastidiosa. Among the 67 isolates from 83 samples, 18 were classified as G-type while 49 were determined to be A-type.

Colony morphology. Detailed microscopic examination of $X$. fastidiosa strains using direct light from different angles revealed significant colony morphology variations. In general, there were two major colony morphotypes, smooth and "pit"-like, namely. The smooth type was circular or occasionally slightly irregular, convex with entire margins (Fig. 3A). All of the observed Ggenotype strains showed this colony morphotype. The "pit"-like morphotype was characterized by its granular rough appearance on the outskirt colony surface. The central portion was largely convex or pulvinate (Fig. 3B). The two-steps or umbanate morphology could give the appearance of pit formation when observed through the base of the petri dish under a stereo binocular microscope with fiber-optic bifurcated lights. The colony form ranged from circular to spindle shaped and the spindle shape seemed to be associated with streak marks on the medium surface.

All of the "pit"-like colony strains were further confirmed to be genomically A-type by PCR using both the 16S rDNA SNP primers and RST31-RST33. The "pit"-like colony morphotype was the predominant type among all A-type strains from our ALSD samples. A small group of A-type strains showed a non"pit"-like colony morphology. They were in a somewhat irregular form and convex with undulate margin (Fig. 3D). The Dixon strain, which was a high passage culture, belonged to this type under our cultivation conditions.

Figure 3C and D representatively shows the presence of mixed colonies from two individual petioles from orchard D (Table 1). However, one colony type was always predominant, estimated to be at least $99 \%$ of the colonies on the primary isolation plates. This may partially explain why both the three and the four primer multiplex PCR consistently detected only one genotype, either Gtype or A-type, in our assays. The DNA templates from the predominant genotype suppressed those from the minority genotype during the PCR process. Although a weaker DNA band of the corresponding genotype could sometimes be visualized (Fig. 2A, strain Dixon; Fig. 2B, strain Kern R 76), we interpret that these resulted from nonspecific amplifications.

\section{DISCUSSION}

In prokaryotes, the $16 \mathrm{~S}$ rDNA loci are commonly regarded as highly conserved and are of taxonomic value for a species de-

\section{Strain}

PCR Primers:

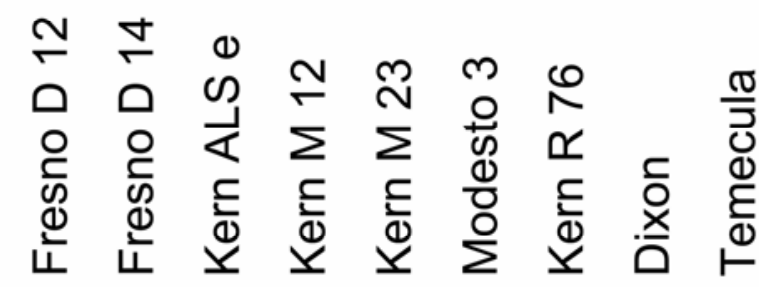
A
Teme150fc/Teme454rg /16S1031r

Beme150fc/Teme454rg/
Dixon454fa / Dixon1261rg

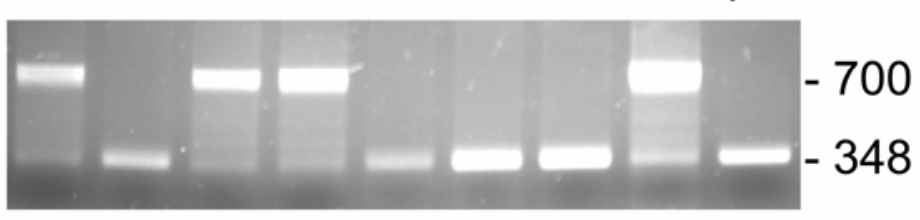

C RST31/33
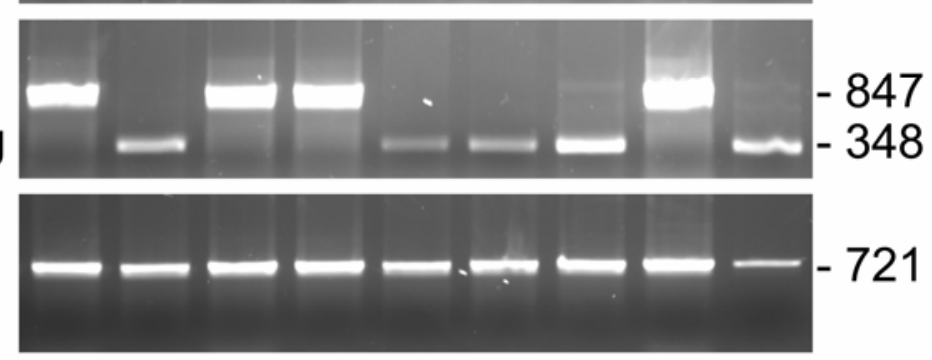

D RST31/33 Rsal digestion

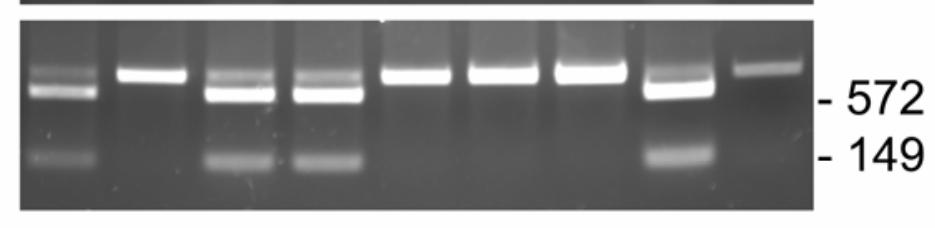

\section{A $\quad G \quad A \quad A \quad A \quad G \quad G \quad G \quad A \quad G$ \\ Genotype}

Fig. 2. Polymerase chain reaction (PCR) amplifications of almond leaf scorch isolates from San Joaquin Valley of California using the A, three primer format, B, four primer format, and C, RST31-RST33 primer set. Panel D is the RsaI digestion of RST31-RST33 amplicons. Numbers on the right are DNA fragment size in base pairs. 
scription. It has, however, been a general perception that $16 \mathrm{~S}$ rDNA sequences are not suitable for the classification of bacteria below the species level because of the limited amount of DNA polymorphic data. For example, four SNPs could only account for $0.25 \%$ of the $1,545-\mathrm{bp}$ rDNA sequence in $X$. fastidiosa. As more genome sequences are identified, particularly those multiple coverage sequences from whole genome sequencing efforts, SNPs of high taxonomic and evolutionary value are being discovered. Therefore, SNPs in $16 \mathrm{~S}$ rDNA are valuable for strain differentiation.

One major concern is sequence errors. In other words, the SNPs must not be an artifact. The source of sequence variations has been discussed extensively by Clayton et al. (8), which include laboratory error, biological source variations, within- and between strain variations, and interoperon differences. Many previously submitted $16 \mathrm{~S}$ rDNA sequences in the GenBank database were possibly single passed sequences with a potentially high error rate. This study was not designed to identify the source of variations in all the rDNA sequences. Rather, our effort was to identify important SNPs based on sequences from the complete genome sequencing projects and substantiate these SNPs by extracting information from other $16 \mathrm{~S}$ rDNA sequences of different sources, and to test these SNPs by screening a large number of strains from ALSD samples.

Our objective was to determine if both G-type and A-type or non-G-type $X$. fastidiosa strains simultaneously occurred in ALSD orchards in California. Results from the 16S rDNA SNP typing were further substantiated by RFLP analysis of the RST31RST33 locus (Fig. 2) and by correlation with the previously undescribed colony morphology of $X$. fastidiosa ALSD strains (Fig. 3 ). It is also noted that multisequence comparisons identified position 1338 as an SNP separating the CVC group from other $X$. fastidiosa (data not shown), suggesting a possibility of performing a similar SNP analysis on this economically important strain in the future.

ALSD was previously reported to be caused by the same $X$. fastidiosa strain or pathotype as the one causing PD of grapevine $(10,18)$. The report by Mircetich et al. (18) is based on vector
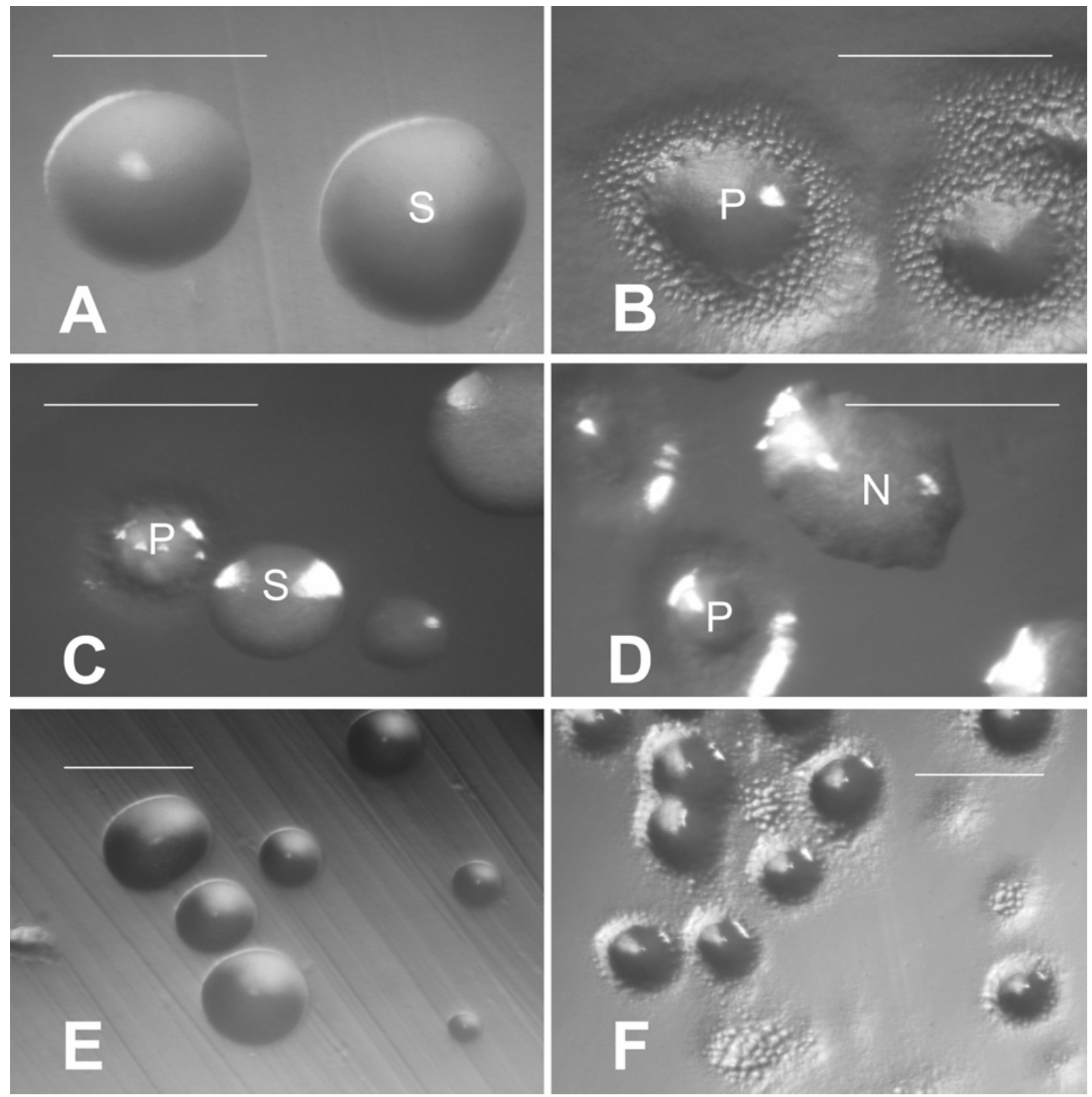

Fig. 3. Microscopic colony morphology of different Xylella fastidiosa genotypes isolated from almond leaf scorch disease samples. A, Smooth type; B, "pit"-like type; C, "pit"-like and smooth type; D, "pit"-like and non-"pit"-like A-type; and $\mathbf{E}$ and $\mathbf{F}$, triple-cloned colonies from a single almond petiole (E, smooth G-type; and $\mathbf{F}$, "pit"-like A-type). Bar scale $=0.5 \mathrm{~mm}$. 
transmission experiments and no strain variation information was described. Using PD2 medium, Davis et al. (10) isolated the causal agents of PD and ALSD, but strain variation was not investigated although the bacterial strains were shown to crossinfect each host. Based on pathogenicity experiments and RAPD analysis of total genomic DNA, Almeida and Purcell (2) recently reported that ALSD was in fact caused by at least two $X$. fastidiosa genotypes, a grape type and an almond type. Their data also suggested that there could be subgroups within the almond type; yet, the issue of mixed genotype infection in ALSD was not discussed.

Our data clearly indicate that at least two genotypes of $X$. fastidiosa coexisted in the ALSD samples collected from selected orchards within California. The strongest evidence comes from one ALSD survey in an orchard in Kern County in October 2003 (Table 1, orchard D). In this survey, the approximately 14.6-ha orchard was systematically evaluated for the presence of ALSD symptoms. Eighty-three symptomatic trees were identified and samples were collected accordingly. Out of the 67 isolates collected from 83 symptomatic samples, 49 were classified as A-type (73\%) and the remainder classified as G-type.

Second, at least in one case, two genotypes of $X$. fastidiosa were found in the same infected leaf petiole or almond tree. Because one population was predominant over the other, the multiplex PCR in the current format could not conclusively determine the presence of both genotypes from the same culture sample. However, the simultaneous presence of two genotypes in the same orchard, plus the lack of evidence for vector specificity, prompted us to investigate the scenario of mixed genotypes in the same tree. Detailed microscopic observation of early passage culture (presumably mixed or not pure) from the same leaf petiole revealed the presence of at least two colony types of $X$. fastidiosa (Fig. 3C and D). Efforts were made to separate and triple-clone the two colony types (Fig. 3E and F), and PCR results further confirmed the association of colony types with $16 \mathrm{~S}$ rDNA SNP types and RFLP types of the RST31-RST33 locus (data not shown).

Description of $X$. fastidiosa colony morphology has been limited. Early reports included both smooth and rough colony types on PW agar with no association to specific strains $(9,29)$. A PWG plate is essentially the same as a PW agar plate, but agar is replaced by Gel-Rite in the former, making the medium much more transparent for microscopic observation. The "pit"-like Atype colony morphology is significantly different from the non"pit"-like A-type (Fig. 3D, E, and F). However, only 1 out of the 49 A-type strains isolated from orchard D in Table 1 was predominantly non-"pit"-like. Further studies are needed to determine whether these two phenotypes are genetically distinct. The persistence of colony morphology in high passage subculture and different types of media also needs to be evaluated. In two previous reports $(2,12)$, a genotype other than that of the Dixon strain was found, but no description of colony morphology was provided.

The biological implication of SNPs used in this study is not known. Yet, they can serve as valuable genetic markers for pinpointing a genotype from the bacterial population. Previous ecological discussions have implied that SNPs could lead to, or be correlated with, niche expansion that form specialized strains and even novel biological species $(19,28)$. The combination of SNP profiles groups the 38 sequences $(4,7,16,20,24,27)$ into four genotypes. While the variations of some strain sequences need further clarifications, the SNP grouping was, in general, consistent with the reports based on nearly complete $16 \mathrm{~S}$ rDNA sequence analysis $(7,16,20)$, i.e., a grape PD group, a CVC group, a group of mixed host origins including almond, and a genetically distinct group represented by a pear leaf scorch strain from Taiwan. A scheme of subspecies of $X$. fastidiosa has recently been proposed for the PD group, CVC group, and the group of mixed host origins (23). SNPs in the 16S rDNA were not used in the study. A more comprehensive SNP analysis in $16 \mathrm{~S}$ rDNA may lead to the establishment of a standardized frame-work assisting $X$. fastidiosa subspecies grouping.

It is worth mentioning that the SNP profile of a single California ALSD strain belonged to the $16 \mathrm{~S}$ rDNA CVC group previously reported from Brazil (20). In that report, sequence analysis from both $16 \mathrm{~S}$ rDNA and GyrB loci clustered the almond strain with CVC strains. The same almond strain was not included in this study. In an RFLP study, Chen et al. (6) grouped the same almond strain into the grape PD strain cluster. Serological tests also suggested this strain to be more related to PD strain (29). Further study is needed to clarify such differences.

In summary, we report the simultaneous presence of at least two genotypes of $X$. fastidiosa within ALSD samples collected from orchards in the San Joaquin Valley of California. The interaction of different $X$. fastidiosa genotypes and the almond host as related to disease development remains to be studied. Understanding the variations of cultivar susceptibility to different $X$. fastidiosa strains could influence the study of ALSD epidemiology and resistant germplasm collections. The existence of mixed phenotypes also addresses the need for assurance of culture purity in $X$. fastidiosa strain characterization. The method described in this manuscript can be further modified for strain quantification and in vivo detection.

\section{ACKNOWLEDGMENTS}

Part of this research was supported by UC-DNR fund. We thank R. Alvarez and G. Phillip for technical support.

\section{LITERATURE CITED}

1. Alma, A., Davis, R. E., Vibio, M., Danielli, A., Bosco, D., Arzone, A., and Bertaccini, A. 1996. Mixed infection of grapevines in northern Italy by phytoplasmas including 16S rRNA RFLP subgroup 16SrI-B strains previously unreported in this host. Plant Dis. 80:418-421.

2. Almeida, R. P .P., and Purcell, A. H. 2003. Biological traits of Xylella fastidiosa strains from grapes and almonds. Appl. Environ. Microbiol. 69:7447-7452.

3. Banks, D., Albibi, R., Chen, J., Lamikanra, O., Jarret, R. L., and Smith, B. J. 1999. Specific detection of Xylella fastidiosa Pierce's disease strains. Curr. Microbiol. 39:85-88.

4. Bhattacharyya, A., Stilwagen, S., Reznik, G., Feil, H., Feil, W. S., Anderson, I., Bernal, A., D’Souza, M., Ivanova, N., Kapatral, V., Larsen, N., Los, T., Lykidis, A., Selkov, E., Jr., Walunas, T. L., Purcell, A., Edwards, R. A., Hawkins, T., Haselkorn, R., Overbeek, R., Kyrpides, N. C., and Predki, P. F. 2002. Draft sequencing and comparative genomics of Xylella fastidiosa strains reveal novel biological insights. Genome Res. 12:1556-1563

5. Chen, J., Banks, D., Jarret, R. L., Chang, C. J., and Smith, B. J. 2000. Use of $16 \mathrm{~S}$ rDNA sequences as signature characters to identify Xylella fastidiosa. Curr. Microbiol. 40:29-33.

6. Chen, J., Chang, C. J., Jarret, R. L., and Gawel, N. 1992. Genetic variation among Xylella fastidiosa strains. Phytopathology 82:973-977.

7. Chen, J., Jarret, R. L., Qin, X., Hartung, J. S., Banks, D., Chang, C. J., and Hopkins, D. L. 2000. 16S rDNA sequence analysis of Xylella fastidiosa strains. Syst. Appl. Microbiol. 23:349-354.

8. Clayton, R. A., Sutton, G., Kinkle, S. P., Jr., Bult, C., and Fields, C. 1995. Intraspecific variation in small-subunit rRNA sequences in GenBank: Why single sequences may not adequately represent prokaryotic taxa. Int. J. Syst. Bacteriol. 45:595-599.

9. Davis, M. J., French, W. J., and Schaad, N. W. 1981. Axenic culture of the bacteria associated with phony disease of peach and plum leaf scald. Curr. Microbiol. 6:309-314.

10. Davis, M. J., Thomson, S. V., and Purcell, A. H. 1980. Etiological role of a xylem-limited bacterium causing Pierce's disease in almond leaf scorch. Phytopathology 70:472-475.

11. Freitag, J. H. 1951. Host range of Pierce's disease virus of grapes as determined by insect transmission. Phytopathology 41:920-934.

12. Hendson, M., Purcell, A. H., Chen, D., Smart, C., Guilhabert, M., and Kirkpatrick, B. 2001. Genetic diversity of Pierce's disease strains and other pathotypes of Xylella fastidiosa. Appl. Environ. Microbiol. 67:895903.

13. Hill, B. L., and Purcell, A. H. 1995. Acquisition and retention of Xylella fastidiosa by an efficient vector, Graphocephala atropunctata. Phytopathology 85:209-212. 
14. Hopkins, D. L. 2001. Xylella fastidiosa. Pages 201-213 in: Laboratory Guide for Identification of Plant Pathogenic Bacteria. N. W. Schaad, J. B. Jones, and W. Chun, eds. The American Phytopathological Society, St. Paul, MN.

15. Lee, I.-M., Bertaccini, A., Vibio, M., and Gundersen, D. E. 1995. Detection of multiple phytoplasmas in perennial fruit trees with decline symptoms in Italy. Phytopathology 85:728-735.

16. Mehta, A., and Rosato, Y. B. 2001. Phylogenetic relationships of Xylella fastidiosa strains from different hosts, based on 16S rDNA and 16S-23S intergenic spacer sequences. Int. J. Syst. Bacteriol. Evol. Microbiol. 51:311-318.

17. Minsavage, G. V., Thompson, C. M., Hopkins, D. L., Leite, R. M. V. B. C., and Stall, R. E. 1994. Development of a polymerase chain reaction protocol for detection of Xylella fastidiosa in plant tissue. Phytopathology $84: 456-461$.

18. Mircetich, S. M., Lowe, S. K., Moller, W. J., and Nyland, G. 1976. Etiology of almond leaf scorch disease and transmission of the causal agent. Phytopathology 66:17-24.

19. Perutz, M. F. 1983. Species adaptation in a protein molecule. Mol. Biol. Evol. 1:1-28.

20. Rodrigues, J. L., Silva-Stenico, M. E., Gomes, J. E., Lopes, J. R., and Tsai, S. M. 2003. Detection and diversity assessment of Xylella fastidiosa in field-collected plant and insect samples by using 16S rRNA and gyrB sequences. Appl. Environ. Microbiol. 69:4249-4255.

21. Rozen, S., and Skaletsky, H. J. 2000. Primer3 on the WWW for general users and for biologist programmers. Pages 365-386 in: Bioinformatics Methods and Protocols: Methods in Molecular Biology. S. Krawetz and S. Misener, eds. Humana Press, Totowa, NJ.

22. Schaad, N. W., Opgenorth, D., and Gaush, P. 2002. Real-time polymerase chain reaction for one-hour on-site diagnosis of Pierce's disease of grape in early season asymptomatic vines. Phytopathology 92:721-728.

23. Schaad, N. W., Postnikova, E., Lacy, G., Fatmi, M., and Chang, C. J. 2004. Xylella fastidiosa subspecies: X. fastidiosa subsp. piercei, subsp. nov., $X$. fastidiosa subsp. multiplex subsp. nov., and $X$. fastidiosa subsp. pauca subsp. nov. Syst. Appl. Microbiol. 27:290-300.

24. Simpson, A. J., Reinach, F. C., Arruda, P., Abreu, F. A., Acencio, M., Alvarenga, R., Alves, L. M., Araya, J. E., Baia, G. S., Baptista, C. S., Barros, M. H., Bonaccorsi, E. D., Bordin, S., Bove, J. M., Briones, M. R., Bueno, M. R., Camargo, A. A., Camargo, L. E., Carraro, D. M., Carrer, H., Colauto, N. B., Colombo, C., Costa, F. F., Costa, M. C., Costa-Neto, C. M., Coutinho, L. L., Cristofani, M., Dias-Neto, E., Docena, C., ElDorry, H., Facincani, A. P., Ferreira, A. J., Ferreira, V. C., Ferro, J. A., Fraga, J. S., Franca, S. C., Franco, M. C., Frohme, M., Furlan, L. R., Garnier, M., Goldman, G. H., Goldman, M. H., Gomes, S. L., Gruber, A., Ho, P. L., Hoheisel, J. D., Junqueira, M. L., Kemper, E. L., Kitajima, J. P.,
Krieger, J. E., Kuramae, E. E., Laigret, F., Lambais, M. R., Leite, L. C., Lemos, E. G., Lemos, M. V., Lopes, S. A., Lopes, C. R., Machado, J. A., Machado, M. A., Madeira, A. M., Madeira, H. M., Marino, C. L., Marques, M. V., Martins, E. A., Martins, E. M., Matsukuma, A. Y., Menck, C. F., Miracca, E. C., Miyaki, C. Y., Monteriro-Vitorello, C. B., Moon, D. H., Nagai, M. A., Nascimento, A. L., Netto, L. E., Nhani, A., Jr., Nobrega, F. G., Nunes, L. R., Oliveira, M. A., de Oliveira, M. C., de Oliveira, R. C., Palmieri, D. A., Paris, A., Peixoto, B. R., Pereira, G. A., Pereira, H. A., Jr., Pesquero, J. B., Quaggio, R. B., Roberto, P. G., Rodrigues, V., de M. Rosa, A. J., de Rosa, V. E., Jr., de Sa, R. G., Santelli, R. V., Sawasaki, H. E., da Silva, A. C., da Silva, A. M., da Silva, F. R., da Silva, W. A., Jr., da Silveira, J. F., Silvestri, M. L., Siqueira, W. J., de Souza, A. A., de Souza, A. P., Terenzi, M. F., Truffi, D., Tsai, S. M., Tsuhako, M. H., Vallada, H., Van Sluys, M. A., Verjovski-Almeida, S., Vettore, A. L., Zago, M. A., Zatz, M., Meidanis, J., and Setubal, J. C. 2000. The genome sequence of the plant pathogen Xylella fastidiosa. Nature 406:151-157.

25. Sinclair, W. A., and Griffiths, H. M. 2000. Variation in aggressiveness of strains of ash yellows phytoplasmas. Plant Dis. 84:282-288.

26. Thompson, J. D., Higgins, D. G., and Gibson, T. J. 1994. CLUSTAL W: Improving the sensitivity of progressive multiple sequence alignment through sequence weighting, position-specific gap penalties and weight matrix choice. Nucleic Acids Res. 22:4673-4680.

27. Van Sluys, M. A., de Oliveira, M. C., Monteiro-Vitorello, C. B., Miyaki, C. Y., Furlan, L. R., Camargo, L. E., da Silva, A. C., Moon, D. H., Takita, M. A., Lemos, E. G., Machado, M. A., Ferro, M. I., da Silva, F. R., Goldman, M. H., Goldman, G. H., Lemos, M. V., El-Dorry, H., Tsai, S. M., Carrer, H., Carraro, D. M., de Oliveira, R. C., Nunes, L. R., Siqueira, W. J., Coutinho, L. L., Kimura, E. T., Ferro, E. S., Harakava, R., Kuramae, E. E., Marino, C. L., Giglioti, E., Abreu, I. L., Alves, L. M., do Amaral, A. M., Baia, G. S., Blanco, S. R., Brito, M. S., Cannavan, F. S., Celestino, A. V., da Cunha, A. F., Fenille, R. C., Ferro, J. A., Formighieri, E. F., Kishi, L. T., Leoni, S. G., Oliveira, A. R., Rosa, V. E., Jr., Sassaki, F. T., Sena, J. A., de Souza, A. A., Truffi, D., Tsukumo, F., Yanai, G. M., Zaros, L. G., Civerolo, E. L., Simpson, A. J., Almeida, N. F., Jr., Setubal, J. C., and Kitajima, J. P. 2003. Comparative analyses of the complete genome sequences of Pierce's disease and citrus variegated chlorosis strains of Xylella fastidiosa. J. Bacteriol. 185:1018-1026.

28. Weissman, S. J., Moseley, S. L., Dykhuizen, D. E., and Sokurenko, E. V. 2003. Enterobacterial adhesins and the case for studying SNPs in bacteria. Trends Microbiol. 11:115-117.

29. Wells, J. M., Raju, B. C., Hung, H.-Y., Weisburg, W. G., Mandelco-Paul, L., and Brenner, B. J. 1987. Xylella fastidiosa new-genus new-species gram-negative xylem-limited fastidious plant bacteria related to Xanthomonas spp. Int. J. Syst. Bacteriol. 37:136-143. 